\title{
OBSTACLES IN INTER-ORGANIZATIONAL COOPERATION AND HYBRID THREATS
}

\author{
Nebojsa NIKOLIC
}

\begin{abstract}
Inter-organizational cooperation at both national and international level depends on many factors. Some can have negative influence and be perceived as obstacles to efficient inter-organizational cooperation. Obstacles could be caused by bureaucratic rivalries, parochial mentality, rigid organizational rules and procedures, inappropriate information, harmful leadership, etc. Due to a variety of hybrid threats, the logical response of states' leaders should be directed to gathering information from all available sources in order to become resilient and respond adequately to hybrid threats. Identification of obstacles and evaluation of their influence may contribute to the ability to resolve problems, to avoid obstacles or, at least, to clarify neds and opportunities for improvement.
\end{abstract}

Keywords: Inter-organizational, cooperation, hybrid warfare, defence, security, resilience.

\section{Introduction}

This paper presents an attempt to consider relations between two phenomena (hybrid warfare and inter-organizational cooperation), and these relations have drawn the attention of researchers and professionals in the field of security and defence studies. Many questions could be raised in discussions about hybrid warfare: What is hybrid warfare? Does it really exist? What are the indicators for hybrid warfare? Whose responsibility is it to counter hybrid warfare? Is there empirical evidence of hybrid warfare? How can a hybrid threat be recognized? How can hybrid warfare be detected? How should hybrid threats be countered? Finally, how can a hybrid war be won? There are many indicators of fundamental changes in many aspects of the physiognomy of modern warfare. Researchers are trying to understand modern warfare ${ }^{1}$ and conflicts in general. ${ }^{2}$ Classical descriptors of war are blurred as there are problems in identifying opponents: who makes war against whom - state or non-state actors; what are the real reasons for starting a war and who initiates it; (official) declaration of war and (official) ending of war; determination of war zone; and so on. Many determinants become fuzzy, obscure and confusing. 
To understand "hybrid warfare," it is useful to rely on a classical definition of war in general. Connections between politics and warfare are well known and well expressed in a statement by Carl von Clausewitz: "War is the continuation of politics by other means." In that sense, war and peace could be considered a continuum. Efforts to understand modern conflicts have generated a new term: hybrid warfare. ${ }^{3}$ While the term itself is good enough as a singular label for a huge set of different kinds of activities and issues, including armed conflicts, it is questionable if the expression "declare hybrid warfare," actually refers to a new kind of warfare. Arguably, the concept of peace-war continuum leads to a discussion about another term: "hybrid peacefare," which has been generated on a similar logic. Actually, it could be justified because, as we will see in this study, hybrid warfare in its broader perception contains activities that may be observed during a period of peace comprising many other domains (politics, economy, energy, transportation, legislation, culture, education, media, sport, etc.).

On the other hand, the organizational structure of a traditional state still follows traditional schemes of division of labour, organizational forms and hierarchies, activities and relations. However, modern security threats have demonstrated much greater development dynamics and generated new forms of appearance. In the contemporary globalized world of networked and mutually dependent states, there are many levers of power (not only political, but economic, social, financial, media related, etc.) which could be applied in order to achieve goals of such importance and kind for which in the past states had to wage wars to get similar results. International and intranational conflicts in modern times have become extremely complex and fuzzy because all kind of boundaries have been crossed.

So, what is the connection between the two concepts introduced in this study: on the one hand, inter-organizational cooperation, and on the other, hybrid warfare? In short, hybrid threats generate new and greater demands from states. A single organization, ministry, department or agency which faces hybrid warfare challenges usually recognizes a shortage of resources, knowledge or mandate to successfully respond to them. Because of that, single organizations should address each other to share burden, to disseminate information and knowledge, and to synergize efforts so that they could successfully counter hybrid threats.

The sections are dedicated to the following: a short presentation of the hybrid warfare genesis and the need for inter-organizational cooperation; evaluation of the power and limitations of inter-organizational cooperation as a tool for countering hybrid threats, realized through SWOT analysis; and the last section will point out the obstacles to a successful and efficient inter-organizational cooperation. 


\section{Diversity of Hybrid Warfare}

Physiognomy of contemporary conflicts has a dynamic character with growing trend of expanding forms. The term hybrid warfare is relatively a new one. It has evolved from attempts to understand and mark the specific nature of contemporary conflicts in a globalized world. It is considered that one of the first public use of the term "hybrid warfare," in the current dominant perception of the term, was performed by a Marine Corps general, General James Mattis, at the Defense Forum, organized by the Naval Institute and Marine Corps Association on September 8, 2005. General Mattis together with Frank Hoffman, a researcher, have developed the main idea of hybrid warfare. $^{4}$

However, there were some earlier ${ }^{5}$ references to the terms: "hybrid war," "hybrid force," and "hybrid operations." It was done in a bit narrow context referring to relations among some military services (branches) in the USA military. Namely, hybrid warfare was seen as an intersection zone between special operations and conventional operations. The basic idea in this early work is that the US Marine Corps has always been a hybrid force able (trained, equipped, developed, and managed) to perform both conventional and special operations. This "double capacity" of the US Marine Corps is regarded as the main difference between the US Marine Corps and the other US military services and their special operational units. Another interesting aspect is the perception of continuity of hybrid warfare ("hybrid warfare occurs across a continuum"), ${ }^{6}$ containing conventional and unconventional attributes.

At present we can add some other aspects to this continuum, such as:

- time dimension (time border between war and peace is blurred);

- terrain determinants (frontlines become fuzzy, area of operation spreads across communication zones, and the whole theatre of operations may even reach a global level);

- even issues that opponents at war have become dynamic (alliances become variable, as well as action intensities, goals, etc.);

- nature and content of hybrid wars may refer to pure armed conflicts but also to almost all other fields (economy, transportation, trade, financial market, sport events, social events, media, etc.).

Despite its current widespread significance, there is not a single recognizable definition of the term "hybrid warfare." In its essence, as well as by logical deduction, it could be suggested that hybrid warfare is a mixture or blend of something: something traditional (already existing), known, regular and some additional, different or new (irregular) entities, factors and characteristics related to the war. 
One of the definitions of hybrid warfare is as follows: "Hybrid warfare is a conflict executed by either state and/or non-state threats that employs multiple modes of warfare to include conventional capabilities, irregular tactics, and criminal disorder." Hybrid warfare is considered to be an intersection of irregular and conventional warfare, plus a domain containing a full spectrum of criminal activities and a whole set of cyber warfare. In simple words, hybrid warfare contains all possible activities across the whole range of human activities, that are undertaken by an adversary against their opponent in order to achieve certain objectives.

The term hybrid warfare became very popular after the Israel-Hesbollah war in 2006. The specific character of this armed conflict and its immediate consequences at the battlefield confirmed that a non-state actor entered the war well prepared and well equipped for applying deadly force against regular armed forces of state actor, including projection of power far from the front line. The following facts ${ }^{8}$ are good indicators for the respective level of military power, developed by this non-state actor: it launched a few thousand rockets aiming northern Israel, which resulted in thousands of casualties (killed and wounded) among the civilian population, and evacuation of thousands of people from threatened areas; a broad engagement of medium and longrange anti-tank missiles (which hit 48 out of 400 Israeli tanks); one aircraft and a few helicopters were also lost; and even one warship of Israeli Navy was damaged (corvette "Hanit" was hit at ten nautical miles from coastline near Beirut, by an anti-ship missile). In addition, the ways of conducting battles, coordination of actions, synchronization of fire, defence lines organization, communication procedures and equipment, used by Hezbollah, showed that Israeli Defence Forces (IDF) met adequate adversary at the conventional battlefield. And the surprise was that a non-state actor succeeded in producing a military force which was capable of conducting conventional military actions that are inherent to state actors.

A new wave of popularity of the term hybrid warfare came with the crisis development in Ukraine. A number of articles, ${ }^{9}$ studies, ${ }^{10}$ and books ${ }^{11}$ have pointed out that the crisis has been an example of hybrid warfare. It has been of a particular interest in a novel approach, studying the phenomenon of hybrid warfare, according to which the narrow purpose of hybrid warfare has been reduced to a regime change. ${ }^{12}$ This upto-date book offers a comprehensive overview of many terms and approaches related to the complex nature of modern warfare and conflicts, while taking under consideration the main or final purpose of different actions (regime change, or change from a current state towards a desired one).

Taking into account all different approaches to hybrid warfare, it could be said that there exist evolutive and revolutive aspects of hybrid warfare. The evolutive aspect takes much more time (and not necessarily more resources) to reach the main goal (regime change, or more precisely: change of regime behaviour; or more generally, 
and in the spirit of Sun Tzu philosophy, compelling adversaries to do what you want without war). The evolutive aspect is related to: a promotion of desired values, discouraging undesired behaviour, negotiations, guided stimuli, trade-offs, obstructions, sanctions, establishment of desired contracts, norms, people, etc.).

On the other hand, revolutive aspect of hybrid warfare is related to: ultimative demands, instigation of civil disobedience, assassinations, unrest support, sabotage, covert armed actions, military intervention, forced regime change, etc.

Response to hybrid threats is also complex (as the threats are), multiphase, long-run and multi-organizational. Also, it is specific due to circumstances related to a specific case of hybrid warfare. Some authors ${ }^{13}$ recognize five response strategies, known as the "Five Ds": De-escalation; Delegitimation; Defence; Denial; and Development.

\section{Enhancing Inter-organizational Collaboration}

The inter-organizational cooperation is a method of coping with uncommon tasks and problems, when regular capacities, mandates, resources or knowledge of the considered organizational entity are not sufficient and when developing of own capacities or obtaining own resources is not possible or not efficient at a given time or other conditions. Inter-organizational collaborations appear in different fields of business, industry, education, public services, etc. Inter-organizational collaboration is of particular importance in public sector in its widest aspect. Lack of resources, knowledge, mandates and time generate innovativeness and rational behaviour among influenced security subjects. An almost obvious solution for a public sector top manager, faced with security threat and all kind of "-lackness," is to look around (starting from "sister departments"), and ask for help. Inter-organizational collaboration in defence related issues is recognized in literature containing hybrid warfare context ${ }^{14}$ along with the use of different terms like comprehensive government approach, whole-of-government-approach, etc.

Inter-organizational collaboration appears in a state where there is a need for it, when at least one organization is interested in starting communication and relations with other organizations. Organizations join each other voluntarily, on the basis of mutual interest, expecting mutual benefits from that exchange. When levels of necessity for cooperation among these organizations are of the same kind and order, then there are good prospects for reciprocal exchange and symmetrical collaboration followed by good will and stable relations. However, there are cases when asymmetry appears and one side attempts to establish power and control over other organization and its resources. Asymmetry is related to interests but is usually supported by other aspects as well such as size, mandate, hierarchical position, preferences of the higher authority, etc. To the weaker partner, asymmetry usually brings organizational con- 
cerns, a feeling of loss of autonomy, injustice, exploitation, manipulation, and at the end, erosion of capabilities and disappearing. By contrast, if the stronger partner in asymmetrical inter-organizational relations has good will and no hidden agenda, a smaller organization can gain disproportional benefit promotion.

Cooperative inter-organizational relations ${ }^{15}$ assume a three-component cyclic process, composed of negotiations, commitments (formal and informal-psychological contracts) and executions, in parallel with constant assessments based on two main characteristics: efficiency and equity. The main point here is highlighting that interorganizational cooperation and relations in general are a process rather than a single step. Achieving a high quality of relations among different organizations is a longterm process that demands determination, perseverance, tolerance, flexibility, adaptability, patience, skilfulness, creativity, information awareness, empathy, etc. Once reaching a good level of inter-organizational relations, they have to be sustained and further developed in a longer period.

Inter-organizational groups are one of the possible modes of inter-organizational collaboration, which has been known in the Management Science for a long time. ${ }^{16}$ Usually formed on a temporary basis, task-oriented, these groups are dedicated to realize inter-organizational cooperation in practice. Once formed and put in operation, those groups develop their own dynamic, structure and capacity to produce some results, as well as some specific internal problems and questions.

Considering issues related to hybrid warfare, it is very useful to use one specific and easy methodological concept from the field of organizational sciences. It is the socalled PESTLE method; the acronym stands for the following factors: P-political, Eeconomical, S-social, T-technological, L-legislative, and E-environmental. The idea of the PESTLE method application in reference with the phenomenon of hybrid warfare is to systematically analyse and develop all possible options of security threats, as well as to identify appropriate organizations, agencies or departments that are most suitable for developing inter-organizational cooperation. A number of influential factors from different domains (PESTLE) have made the situation much more complex in the context of hybrid warfare, due to mutual influences and interference of different issues of different origins. For example, a benign international agreement related to some environmental issues may be adopted thanks to lobbing, interest trading, political or personal pressure and blackmail, effective media campaign, data generated from extensive use of a cutting-edge technology, or factors from other domains. However, once adopted, such international environmental agreements may have strong influence on the national economy and, consequently, to the population and society. It may cause reduction of industrial production and loss of jobs, which may result in social unrest and political instability and prospects for regime change. 


\section{From Blended to Compound Working Groups}

Blended working groups consist of representatives from different organizations or departments. They are a simple mixture of representatives and are more like a meeting group than a working entity. Almost all inter-organizational working groups are blended in the very beginning (at the first meeting), but after some initialization period they evolve (in case of normal cooperation and absence of obstruction among departments) toward a compound category. Compound working groups have closer and stronger internal relations, working schedule and dedication to common goals of the group (previously agreed among departments). Inter-departmental working groups, particularly those who come from the same branch (like some ministry) should be of compound category rather than only blended mixture of formal representatives.

Inter-Departmental Working Groups (IDWG) are one of the modes of interorganizational cooperation which have been frequently used in the defence and security sector. Inter-departmental working groups have some characteristics in common as follows:

- Team orientation. IDWG consists of more individuals that are expected to behave as team members. It is recommended that group decisions reach a consensus.

- Organizational heterogeneity. Members of IDWG come from different departments.

- Members of IDWG have variety of knowledge.

- Diversity in organizational cultures.

- Differences in administrative and working procedures and norms.

- Double loyalty. Members of IDWG are expected to be loyal to their new team-IDWG, however, they have to stay loyal to their original departments.

- Temporal framework. IDWG operates for a limited period, and after that is dismissed.

- Mandate issues (authorization for IDWG members to make decisions or to act; interference of duties and responsibilities).

On the basis of methodology for SWOT analysis (Strengths, Weaknesses, Opportunities, Threats) wider literature reviews and experience, findings could be extracted in the form of a SWOT scheme, shown in Table 1. 
Table 1: Inter-departmental working group's SWOT table.

\section{STRENGTHS}

WEAKNESS

- Expanded information awareness

- Growth of importance by involvement of different stakeholders

- More perspectives

- Equalizing of criteria and approaches

- Synergism

- Efficient use of resources

- Multidirectional (comprehensive) approach

- Adoption of final results
- Additional duties

- Expanded administration

- Time consuming

- Violation of existing hierarchy

- Duplication of responsibilities

- Clash of values and approaches

- Intra-group competition

- Inter-departmental competition

- Different interests

- Parochialism

- Different level of engagement

\section{OPORTUNITIES}

\section{THREATS}

- Key problems detection

- Use of advanced DM methods

- Mutual help

- Burden sharing

- Smart resourcing

- Consensus achieving

- Experience exchange

- Better prioritization

- Advanced readiness for future challenges
- Domination

- Sabotaging

- Deflection (Turning)

- Dissipation

- Deviation of priorities

- Conflicting

- MAO (Mutually assured obstruction)

- Interference

- Rambling, Fuzziness

- Fading

\section{Obstacles to cooperation}

Inter-organizational cooperation is not immune to some internal problems. It could be the case even in the military organization despite the fact that it is an example of a highly organized entity. Problems in inter-organizational relations, communications and cooperative activities may appear among different departments of the ministry, headquarter departments, different agencies or services. ${ }^{17}$ Inter-organizational problems could arise due to many different reasons:

- organizational barriers;

- lack of information; 
- bad communication;

- poor organizational and working procedures;

- stereotypes;

- bureaucratic rivalries;

- differences in organizational cultures;

- overspecialization;

- extreme secrecy;

- corruption;

- lack of honour and ethics;

- lack of professionalism;

- weak competences;

- $\quad$ shortage of tolerance;

- parochial mentality and disagreements;

- top managers personal animosity;

- envy, etc.

It is a task for supreme managers, department chiefs and agency leaders to find, create and sustain, allow and enable channels for cooperation and make their organizations complementary to each other rather than rival and competitive. Some of the above obstacles could be resolved with tools and methods of organizational improvement, rearranging of business processes, improvement of communication skills, advanced training, etc. The phenomenon of interdepartmental, interagency, interorganizational work could be interpreted as a consequence of the weaknesses experienced by existing organizational entities that had to find a way to cope successfully with external threats. It is not only the case with public sector organizations, but also with players in the market economy, even taken at a global level. Some authors ${ }^{18}$ point out that companies as well as states have to make a lot of efforts in finding and creating innovative organizational forms if they want to hold and advance their positions and wealth. Some of their findings ${ }^{19}$ offer future organizational entities of the 21st century possible solutions that could be summarized as follows: Innovative Change; Collaboration; and Networking.

The need for Innovative Change comes from the stance that classical organizational designs will not be capable enough of dealing with contemporary challenges as well as opportunities, at least in regard to a desired efficiency and effectiveness, available resources and other limitations. There are a few terms that are well known in the context of military organizational changes: Transformation, Reform, Transition, etc. This time, however, the centre of gravity is the Innovative aspect of the organizational 
transformations. The Collaboration principle implies that organizations have to establish, sustain and continuously develop their capabilities and procedures to secure effective mutual communication, coordination and cooperation. Organizational Networking is the next step towards qualitatively higher level of the collaboration. Organizations will have to permanently communicate (organizationally, technically, culturally) with a large number of other organizational entities of different kind, size, culture, interest, etc.

However, factors related to personal characteristics of the top managers (end of the list: envy, animosity, parochialism, intolerance, etc.) are not easy to change. Unfortunately, some factors usually may have a bad impact on groups. For example, corruption is usually accompanied by lack of professionalism, lack of competence and degenerated honour, lack of tolerance and abundance of parochialism, animosity, and envy.

Top leaders of these organizations have the greatest responsibility for achieving success in interdepartmental cooperation. Their behaviour, competences, management style, intellectual capacity and personal character may have a decisive influence on interdepartmental cooperation. Bad leadership behaviour is also known as destructive or toxic leadership, ${ }^{20}$ and the following indicators of bad leadership may directly violate inter-organizational cooperation:

- poor organizational vision and professional awareness (lack of capacity to create good organizational vision, lack of fairness in differentiating and separating organizational goals from personal interest; inability to perform permanent professional observing, gathering, selection, and interpretation of appropriate information, relevant to the organization and its system environment);

- $\quad$ poor decision making (making decisions without enough information, inability to structure a problem, inability to perceive a possible set of options for resolving a problem situation development, inability to understand a longterm view; reluctance to involve advanced methods, tools and technologies; reluctance to change, to apply innovative thinking and multi-disciplinary approach; reluctance to delegate tasks to subordinates; propensity to takeover a prescribed piece of autonomy and rights of subordinate; affinity to seclude into their own backyard and parochialism; affinity to hide behind higher authorities and secrecy, etc.);

- ineffective communication, negotiation, coordination, management and leading (lack of skills, qualifications and professional experience; inability to deal with new technology and change; over-control and micro-manage; inability to motivate subordinates; inability to lead through personal example; 
favoritism; double-standards; tribalism; parochialism; depreciation; envy; poltroonery, etc.).

It is not possible to have any kind of inter-organizational cooperation without at least a formal consent of the chiefs of the organizations at stake. Top managers' strong will and readiness for enabling and stimulating collaboration are irreplaceable.

Problems in cooperation may arise even in cases of cooperation among similar entities (armed forces, police, and security agencies) due to differences in internal organizational issues (working procedures, rules, organizational culture, etc.). There is enough space and need for development and elaborating procedures for cooperation and experience exchange. For example, in a research ${ }^{21}$ it has been explained in detail the close cooperation in the field between military and other organizations responsible for securing a high-level international political meeting (such events could pose a threat to the highest political leadership and present a potential security violation aim, which is certainly a form of hybrid threat). In the mentioned research it was found out that forms of similar inter-organizational and task-based temporary cooperation could be seen in the future as almost a normal mode of interagency cooperative engagement.

\section{Conclusions}

The crisis in Ukraine and the civil war in Syria are regarded in literature as up-to-date examples of hybrid warfare. Following the concept of hybrid warfare and some of the definitions of the hybrid warfare, the list can be expanded to Libya, Georgia, Iraq, former Yugoslavia, etc. Not to miss the newest case of July 2016, the Cu d'État attempt in Turkey which has become a contemporary prime challenge for research communities. In most cases, there is a mixture of external threats (political, economic, military), arranged and applied in a longer period against mentioned states in parallel with a combination of internal antagonisms (social, economic, religious, political, tribal, national, etc.) that are additionally stimulated by different factors (either internal or external) in order to bring those states and societies at the point of open escalation, violence and conflicts. However, the situation of "controlled chaos" has a tendency to develop itself into uncontrollable chaos producing many undesired effects, additional engagements and costs, which usually lead to enduring or at least longrange crises.

The destructive potential, that lies in all possible diverse forms and activities of hybrid warfare, makes single organizations or agencies quite inferior, and thus forces "sole players" to collaborate with others on a permanent basis. Almost all contemporary conflicts that are described as hybrid demand complex respond, which is possible only through engagement of capabilities, resources, mandate and knowledge of 
many different organizations, departments and agencies at national level and international level as well.

The phenomenon of interdepartmental, interagency, inter-organizational work could be interpreted as a consequence of the weaknesses experienced by existing organizational entities that had to find a way to cope successfully with external threats. The future of the $21^{\text {st }}$ century organizational entities could be summarized in the following way: situational awareness about external factors, agility and resilience, innovative change (military transformations, reforms, transitions, etc.) towards organizational self-improvements; collaborative behaviour, and networking. Inter-organizational cooperation is an adequate, and perhaps the best, response of society and nation states towards hybrid threats and hybrid warfare. At the same time, inter-organizational cooperation on defence and security issues is a complex challenge for practitioners and researchers, given the long list of numerous potential obstacles.

\section{Notes}

1 John Arquilla and David Ronfeldt, Swarming and the Future of Conflict (Santa Monica, CA: RAND Corporation, National Defense Research Institute, 1999).

2 Antoine Bousquet, The Scientific Way of Warfare (New York: Columbia University Press, 2009).

${ }^{3}$ Frank Hoffman, "Conflicts in the 21st Century: The Rise of Hybrid Wars," Potomac Institute for Policy Studies, Arlington, Virginia, December 2007.

4 Hoffman, "Conflicts in the 21st Century: The Rise of Hybrid Wars."

${ }^{5}$ Robert Walker, Spec Fi: The United States Marine Corps and Special Operations, Master of Science Thesis (Monterey, CA: Naval Postgraduate School, December 1998).

6 Walker, Spec Fi: The United States Marine Corps and Special Operations.

7 Davi M. D’Agostino, Hybrid Warfare, Report GAO-10-1036R (Washington, D.C.: Government Accountability office, September 2010).

8 Anthony Cordesman, Lessons of the 2006 Israeli-Hezbollah War (Washington, D.C.: Center for Strategic and International Studies, 2007).

9 Merle Maigre, "Nothing New in Hybrid Warfare: The Estonian Experience and Recommendations for NATO," Policy Brief. Foreign Policy Program. (GMF - The German Marshall Fund, February 2015).

${ }^{10}$ Michael Miller, Hybrid Warfare: Preparing for Future Conflict (Maxwell Air Force Base, AL: Air War College, February 2015).

${ }^{11}$ Andrew Korybko, Hybrid Wars: The Indirect Adaptive Approach to Regime Change (Moscow: Institute for Strategic Studies and Predictions, 2015).

${ }^{12}$ Korybko, Hybrid Wars: The Indirect Adaptive Approach to Regime Change.

${ }^{13}$ Matthew Rhodes and Ruta Buneviciute, "Baltic and Central European Security After the Ukraine Crisis," Security Insights 11 (March 2015), accessed April 4, 2018, http://www.marshallcenter.org/mcpublicweb/en/nav-fix-sec-insights/2184-art-pubs-secinsights-11-full-en.html. 
${ }^{14}$ Nathan Freirer, “The Defense Identity Crisis: It's a Hybrid World," Parameters 39, no. 3 (Autumn 2009): 81-94.

${ }^{15}$ Peter Ring and Andrew van den Ven, "Developmental Processes of Cooperative Interorganizational Relationship," Academy of Management Review 19, no. 1 (1994), 90-118.

${ }^{16}$ Janice Schopler, "Interorganizational Groups: Origins, Structure, and Outcomes," Academy of Management Review 12, no. 4 (1987): 702-713.

${ }^{17}$ Walker, Spec Fi: The United States Marine Corps and Special Operations.

${ }^{18}$ Raymond Miles, Charles C. Snow, Øystein Fjeldstad, Grant Miles, and Christopher Lettl, "Designing Organizations to Meet $21^{\text {st }}$-Century Opportunities and Challenges," Organizational Dynamic 39, no. 2 (2010): 93-103.

${ }^{19}$ Miles et al., "Designing Organizations to Meet $21^{\text {st }}$-Century Opportunities and Challenges."

${ }^{20}$ Anthony Erickson, Ben Shaw, Jane Murray, and Sara Branch, "Destructive Leadership: Causes, Consequences and Countermeasures," Organizational Dynamics 44, no. 4 (2015): 266-272.

${ }^{21}$ David Barr, "The Kananskis G8 Summit: A Case Study in Interagency Cooperation," Canadian Military Journal 4, no 4 (Winter 2003-2004): 39-46.

\section{About the Author}

Nebojsa Nikolic is a research associate at the Strategic Research Institute of the Serbian Ministry of Defense. Prior to academic work at the Institute and at the Military Academy, he performed various duties in military units. His research interests include decision making theory, strategic management, multi-criteria ranking problems, simulation, logistics and other disciplines relevant to defense and military organizations. E-mail: nebojsa2008_g@yahoo.com. 